\title{
Recurrence of neural tube defect in a group of at risk women: a 10 year study of Pregnavite Forte F
}

\author{
M Holmes-Siedle, R H Lindenbaum, A Galliard
}

It is now more than a decade since Smithells et $a l^{1}$ first reported an apparent reduction in the recurrence rate in women at risk for a neural tube defect (NTD) when they were supplemented with Pregnavite Forte $F$ around the time of conception. A multicentre study ${ }^{2}$ and a further report by Smithells $e t a l^{\beta}$ support this observation. We summarise the findings of our own 10 year study, which adds to the evidence that vitamin treatment is associated with a beneficial lowering effect on the recurrence rate.

We studied all pregnancies going beyond 12 weeks' gestation in a group of 164 women who had previously carried a fetus with NTD. Eight of these women had twice carried an affected fetus. In the first study pregnancy which followed genetic counselling all women received periconceptional vitamin supplementation (Pregnavite Forte F) according to the method of Smithells et al. ${ }^{1}$ A number of these study pregnancies have been reported previously. ${ }^{2}$ There were no recurrences of NTD, but there was one normal stillbirth at 30 weeks and six babies ( 3.6 per cent) had other abnormalities, namely neurofibromatosis, pyloric stenosis, thyroglossal cyst, albinism, left microphthalmia, and left corectopia.

After the first study pregnancy, which was always fully supplemented, 44 women had one further pregnancy, nine had two, and two women had three more pregnancies. Three women who had a further pregnancy were supplemented with a different vitamin preparation and are therefore excluded from the analysis. Also excluded are the further pregnancies of the two women who went to live abroad. A number of pregnancies were unplanned and not supplemented with vitamins. Nearly all planned pregnancies were again fully supplemented. Two patients asked

Neural tube defect recurrences in at risk pregnancies unsupplemented and supplemented with Pregnavite Forte F: pregnancy outcome.

\begin{tabular}{lccccccr}
\hline \multirow{2}{*}{$\begin{array}{l}\text { Study } \\
\text { pregnancy }\end{array}$} & \multicolumn{2}{c}{ Unsupplemented } & & \multicolumn{2}{c}{ Fully supplemented } & \\
\cline { 2 - 3 } & Non-NTD & NTD & & Non-NTD & NTD & Total \\
\hline First & 0 & 0 & & 164 & 0 & 164 \\
Second & 19 & 2 & & 33 & 1 & 55 \\
Third & 4 & 1 & & 6 & 0 & 11 \\
Fourth & 2 & 0 & & 0 & 0 & 2 \\
Total & 25 & 3 & & 203 & 1 & 232 \\
\hline
\end{tabular}

their general practitioners to prescribe Pregnavite Forte F, but were refused, the physicians telling them that they did not need treatment since they had subsequently had a normal pregnancy, and so were no longer at risk for NTD. One of these two patients actually had a recurrence. Three women were prescribed Pregnavite Forte $\mathrm{F}$ by their general practitioners but only after confirmation of the pregnancy. In a further case the woman ran out of tablets and did not resume taking them until she was already six weeks pregnant.

The outcomes of at risk pregnancies are shown in the table. There was one NTD recurrence in the 204 supplemented pregnancies, and there were three in the 28 unsupplemented pregnancies $(p=0.0057$, Fisher's exact test). Three of the recurrences were of anencephaly and occurred in women who had had one previous NTD. One woman, who had previously had two anencephalic pregnancies, gave birth to a male with hydrocephalus (Arnold-Chiari defect) after an unsupplemented pregnancy. The recurrence rate for NTD without vitamin supplementation was $10.7 \%$ (three in 28); with periconceptional vitamin supplementation it was $0.49 \%$ (one in 204). If we analyse only those pregnancies that followed the first study pregnancies (which were always fully supplemented, and in which there were no recurrences), we find three recurrences among 28 unsupplemented pregnancies $(10.7 \%)$ and one recurrence among 40 fully supplemented pregnancies $(2 \cdot 5 \%)$ $(p=0 \cdot 1609$, Fisher's exact test).

Information on social class is available for all but seven of the women in the study. For the first (fully supplemented) pregnancy 95 women were in social classes 1,2 , and $3 \mathrm{NM}$, and 62 in classes $3 M, 4,7$, and 9 ; there were no recurrences of NTD. In subsequent fully supplemented pregnancies, 31 mothers were in social classes 1,2 , and $3 \mathrm{NM}$, and nine in classes $3 \mathrm{M}, 4$, and other; there was one recurrence of NTD in a mother of social class 1 . For the unsupplemented pregnancies 11 mothers were in classes 1,2 , and $3 \mathrm{NM}$, and 17 in $3 \mathrm{M}, 4$, and other; there were two recurrences of NTD in mothers of social class 2 and one in a mother of social class $3 \mathrm{M}$.

For the first study pregnancy (always supplemented) the mean maternal age was 28.57 
years (SD 3.93 years, $n=164$ ). For the further fully supplemented pregnancies mean maternal age was 30.70 years (SD 3.90 years, $n=40$ ); there was one recurrence, at maternal age 32 years. For the unsupplemented pregnancies mean maternal age was 28.64 years (SD 3.91 years, $n=28$ ); the three recurrences of NTD were at maternal ages 26, 32, and 33 years.

These findings add to the growing evidence that vitamin treatment is associated with a lowering of recurrence risk for NTD. ${ }^{3-5}$ Several further points emerge: the majority of at risk women who have taken vitamin supplementation in one pregnancy wish to be supplemented in subsequent pregnancies; there should be a greater awareness of the need to begin vitamin supplementation at least four weeks before conception; the birth of one normal child to a woman with a previous NTD does not greatly reduce the recurrence risks for NTD in a further pregnancy.

While there was an overrepresentation of social classes $3 \mathrm{M}, 4$, and other in unsupplemented pregnancies $(17 / 28)$, all but one of the NTD recurrences were in mothers of social classes 1 or 2 . Younger mothers were more likely to be unsupplemented, but three of the recurrences were at maternal ages above the mean.

\section{Addendum}

Since submission of this paper the report has appeared of the Medical Research Council randomised double blind trial (Lancet 1991;ii:131-7). The MRC Vitamin Study group found a protective effect with folic acid at a daily dose of $4 \mathrm{mg}$ (relative risk $0 \cdot 28,95 \%$ confidence interval 0.12 to 0.71 ), which is compatible with our findings using a multivitamin preparation with one eleventh the dose of folic acid (relative risk 0.046, 95\% confidence interval 0.023 to 0.090 , for all analysed pregnancies, and relative risk $0 \cdot 23,95 \%$ confidence interval 0.12 to 0.44 , for pregnancies following the first study pregnancy).

1 Smithells RW, Sheppard S, Schorah CJ, et al. Possible prevention of neural tube defects by periconceptual vitamin supplementation. Lancet 1980;i:339-40.

2 Seller MJ. Periconceptional vitamin supplementation to prevent recurrence of neural tube defects. Lancet 1985

3 Smithells RW, Sheppard S, Wild J, Schorah CJ. Prevention of neural tube defect recurrences in Yorkshire: final report Lancet 1989;ii:498-9.

4 Sheppard S, Nevin NC, Seller MJ, et al. Neural tube defect recurrence after 'partial' vitamin supplementaton. $\mathcal{f} \mathrm{Med}$ Genet 1989;26:326-9.

5 Nevin NC, Seller MJ. Prevention of neural-tube-defect recurrences. Lancet 1990;i:178-9. 